\title{
THE SUPINE HYPOTENSIVE SYNDROME DURING CONDUCTION ANAESTHESIA FOR THE NEAR-TERM GRAVID PATIENT: CASE REPORTS
}

H. J. Grennell, M.B., Ch.B., And S. L. Vandewater, M.D., F.R.C.P.(c.)*

The NEAR-TERm GRavid Patient seldom lies supine by choice, and when she does she may develop hypotension characterized by weakness, nausea, and feeling of light headedness. This fact has been well demonstrated by Goodson et al., ${ }^{1}$ who have shown the incidence of hypotension in the supine position to be as high as 11.2 per cent. Their interpretation of hypotension was a fall in systolic pressure of $30 \mathrm{~mm}$. $\mathrm{Hg}$ or a systolic pressure below $80 \mathrm{~mm}$. Hg.

Schmidt ${ }^{2}$ proposed two possible mechanisms to explain this hypotension. The first possibility was that the gravid uterus falls backward when the patient is in the supine position, compressing the inferior vena cava, resulting in diminished venous return to the right heart, decreased cardiac output, and hence a fall in systemic pressure. The second proposition suggested "shock," secondary to stimulation of the venous plexus, behind the uterus, with resultant vasodilation and pooling in the area. The former explanation was the more acceptable, particularly in view of the increased venous pressure in the lower limbs which was demonstrated during these hypotensive episodes.

A more frequent occurrence of this syndrome during conduction anaesthesia was suggested by Kennedy et al. ${ }^{3}$ who reported an incidence of hypotension of 17.7 per cent of vaginal deliveries under spinal anaesthesia (modified saddle block). Further, they pointed out that displacement of the uterus to the left (L.U.D.) and so relieving the inferior vena caval compression, was sufficient to restore systemic pressure to control levels in 93.4 per cent of the hypotensive patients. In this series the patients were in the lithotomy position and pooling of blood in the lower limbs was not a factor in the occurrence of hypotension. It would thus seem reasonable to presume that in cases of conduction anaesthesia for caesarian section, the figure of 17.7 per cent incidence of hypotension would be a conservative estimate.

To illustrate this hypotensive syndrome, the following case reports are presented.

Case 1

A 29-year-old patient, para III, gravida IV, was admitted for an elective caesarian section on January 22, 1961.

Obstetrical history. 1957, first pregnancy terminating in a spontaneous vaginal delivery at term; 1958, emergency caesarian section (under general anaesthesia) for placenta praevia; 1959 , spontaneous vaginal delivery at term.

*From the Department of Anaesthesia, Queen's University, Kingston, Ontario. 
Present history. On admission the patient was grossly overweight at 225 pounds (213 at commencement of pregnancy) and complaining of persistent pain in the region of her abdominal scar (previous section). Physical examination other than obesity was negative, blood pressure $120 / 80$, haemoglobin $12.8 \mathrm{gm}$ : urinalysis negative.

Delivery. On January 23, 1961, without premedication, the patient was taken to the O.R. and a polyethylene catheter was inserted in the epidural space at the $\mathrm{L}$ 4-5 interspace, in the sitting position, using a Huber tipped Tuohy needle (\#17). B.P. before procedure was $120 / 80$. Ten c.c. of 2 per cent lignocaine containing $1 / 200,000$ adrenalin was injected through the catheter and the patient was placed in the supine position, followed by a second injection of 10 c.c. of lignocaine. Within $30 \mathrm{sec}$. the blood pressure was recorded at $60 \mathrm{~mm}$. Hg systolic and the patient complained of pain over the left chest, difficulty in breathing, and a feeling of faintness. Oxygen by mask and methoxamine, $5 \mathrm{mg}$. intravenously, were administered without effect. Further increments of methoxamine were given intravenously to a total of $20 \mathrm{mg}$. The systolic pressure continued to fall and became unrecordable At this stage, approximately 3 minutes after the patient had been placed in the supine position, because of the failure to respond to vasopressors, the supine hypotensive syndrome was considered. The patient was turned to the right lateral position, resulting in an immediate rise in systolic pressure to $120 \mathrm{~mm}$. Hg.

After a short interval, the patient was again placed in the supine position, and preparation of the operative site was begun. The assumption of this position was attended by an immediate fall in the systolic pressure to $40 \mathrm{~mm}$. $\mathrm{Hg}$. Further attempts to carry. out the operation were then abandoned and the patient was kept in the lateral position.

Later the same day, 'after the effects of the epidural anaesthetic had worn off, multiple blood pressure recordings were made with the patient in bed in the supine and both lateal positions. No significant change in blood pressure was noted in the rious positions,

On the following day, the patient was premedicated with meperidine $50 \mathrm{mg}$., promethazine $50 \mathrm{md}$ aftopine $0.4 \mathrm{mg}$., and returned to the O.R. one hour later. The systolic pressure in the sitting position was $110 \mathrm{~mm} . \mathrm{Hg}$, and after the patient was placed in the supine position on the O.R. table, it fell to $80 \mathrm{~mm}$. Turning the patient to the left lateral resulted in a rise of pressure to $110 \mathrm{~mm}$. An intravenous drip was started and levallorphan $0.5 \mathrm{mg}$. was given. After resuming the supine position, the patient was prepared and draped. General anaesthesia was rapidly induced with thiopentone $250 \mathrm{mg}$., and gallamine 120 mg., followed by intubation and maintenance with $\mathrm{N}_{2} \mathrm{O} / \mathrm{O}_{2}$ with controlled respiration. Six and one half minutes after induction a male infant was born with an Apgar rating of 9 . As soon as the uterus was emptied, the maternal systolic pressure rose immediately to $110 \mathrm{~mm}$. $\mathrm{Hg}$, and remained at this level.

Case $\mathscr{Z}$

A 30-year-old patient, para I, gravida II, at term was brought to the delivery 
room for vaginal delivery. Previous obstetrical history was normal. Present pregnancy was uneventful. Last known weight was 130. Blood pressure on admission to the delivery room was $115 / 60$. The patient was placed in the right lateral position, and 14 c.c. 2 per cent lignocaine with $1 / 100,000$ adrenalin was injected into the lumbar epidural space at the L 4-5 interspace through a \#17 Huber tipped Tuohy needle.

Following epidural injection, the patient was placed in the lithotomy position. Over a period of 10 minutes the blood pressure fell to $75 / 45$, with the patient appearing pale and sweating and complaining of weakness. Manual displacement of the uterus to the left would lead to an immediate pressure rise to $95 / 55$. With uterine contractions (without displacement) the blood pressure (systolic) would rise to $95 / 100$, then return to 75 with termination of contractions. The hypotensive episodes were accompanied by a slowing of the pulse from a previous $84 / \mathrm{min}$. to $60 / \mathrm{min}$.

A normal infant was delivered by low forceps 20 minutes after introduction of anaesthesia. The Apgar rating was 9 . The maternal pressure immediately rose to $120 / 70$ following delivery and remained at this level. Pressor agents were not used. Ergometrine $0.25 \mathrm{mg}$. were given intravenously 15 minutes after delivery.

\section{Discession}

Since the supine hypotensive syndrome has been drawn to our attention, we have had eight patients exhibit the signs and symptoms of the above syndrome in the last consecutive 100 cases of vaginal delivery under epidural anaesthesia. In each instance, the systolic blood pressure fell to below $80 \mathrm{~mm} . \mathrm{Hg}$ and responded to either displacement of the uterus, or the movement to the lateral position. Not one of these patients exhibited hypotension in the supine position prior to epidural anaesthesia. This is contrary to the findings of Holmes ${ }^{4}$ who recently suggested the use of a supine hypotension test to indicate the severity of fall in blood pressure that can be expected when spinal anaesthesia is used for caesarian section.

One can readily appreciate how sympathetic paralysis in the splanchnic area would exaggerate a tendency towards hypotension due to vena caval obstruction, and it is interesting to speculate that the sudden catastrophic shock that has been reported on innumerable occasions with spinal anaesthesia in obsteterics, has perhaps been due in large measure to the latter cause. The first case report suggests that the usiual methods of resuscitation with pressor agents are of no avail, whereas shifting the uterus or moving the patient to the lateral position could be life saving.

Finally, the signs and symptoms of collapse illustrated in the first case mimic those of an "accidental" total subarachnoid block, and it may be difficult, if not impossible, to differentiate. It is suggested that if severe hypotension should occur after an epidural (or spinal) block, when the patient assumes the supine position, uterine displacement might be carried out first, before assuming the cause to be a high sympathetic block, accidental or otherwise. 


\section{ACKNOWLEDGMENT}

We wish to thank Dr. R. I. Merritt for his assistance and permission to publish the case histories.

\section{REFERENCES}

1. Howard, B. K., Goodson, J. H., \& Mengert, W. F. Supine Hypotensive Syndrome in Late Pregnancy. Obs. Gyn. 1:371 (1953).

2. Schmidt, D. The Hypotensive Syndrome in the Supine Position in Late Pregnancy. New Eng. J. Med.:259: 1219 (1958).

3. Kennedy, R. L.; Friedman, D. L.; Katchia, D. M.; Selmants, S.; \& Smith, R. N. Hypotension during Obstetrical Anesthesia. Anesthesiology 20: 153 (March-April, 1959).

4. Holmes, F. Supine Hypotension in Late Pregnancy. J. Obs. \& Gyn. Brit. Emp. 67: 254 (1960). 